\title{
Design and baseline data in the BAriatic surgery SUbstitution and Nutrition study (BASUN): a 10-year prospective cohort study
}

Gudrún Höskuldsdóttir ${ }^{1,2^{*}}$ D, Karin Mossberg ${ }^{1}$, Ville Wallenius ${ }^{3,4}$, Angelos Al Nimer ${ }^{3,4}$, Wiveka Björkvall ${ }^{3,4}$, Sören Lundberg ${ }^{3,4}$, Carl-Johan Behre ${ }^{5}$, Malin Werling ${ }^{3,4}$, Björn Eliasson ${ }^{1,2+}$ and Lars Fändriks ${ }^{3,6+}$

\begin{abstract}
Background: There is still a lack of knowledge on long-term effects of surgical and non-surgical weight-lowering treatments. BASUN is a prospective study with 10 years of follow-up that will observe the effects and consequences of surgical and medical treatment of obesity. The aims are to cover areas where data on long-term outcomes are lacking, e.g., nutritional deficiencies, substance abuse, psychiatric health, as well as patient-reported outcomes.

Methods: BASUN is a cohort study that recruited study persons with obesity (BMI $\geq 35 \mathrm{~kg} / \mathrm{m}^{2}$ ) referred to the Regional Obesity Centre of Region Västra Götaland. The interventions were Roux-en-Y gastric bypass (RYGB) or Sleeve gastrectomy (SG), or 12 months of structured, multi-professional medical treatment (MT), including very low energy diet, followed by diet and pharmaceutical treatment. The study is not randomized, but based on patients preferences and multidisciplinary assessments. The study persons are examined at baseline, 2, 5, and 10 years with blood tests, measurements and questionnaires. The recruitment period lasted from May 2015 to November 2017.

Results: One thousand one hundred twenty-seven patients were included (74\% female). Three hundred eighty-two patients were accepted for medical treatment, 589 for surgical treatment (388 RYGB and 201 SG) and 156 patients left the study without treatment, leaving a final study population of 971 patients. There were slight differences between the treatment groups with regards to age and BMI. Pharmaceutical treatments, level of education, smoking and marital status were not significantly different between the groups.

Conclusion: This study will follow 971 obese subjects in clinical practice treated with the best surgical or medical methods currently available. It has the potential to evaluate outcomes usually not reported in short-term studies, and to assist in identifying factors that are of importance for the choices of treatment. The main limitations are non-randomization and differences in baseline characteristics. The large number of participants and the length of the prospective follow-up are major strengths of the study. BASUN is designed to identify both early and late benefits and adverse events of treatment of obesity.
\end{abstract}

Trial registration: This trial was prospectively registered on March 03, 2015; NCT03152617.

Keywords: Obesity, Bariatric surgery, Diet, Prospective study, Cohort study

\footnotetext{
* Correspondence: gudrun.hoskuldsdottir@vgregion.se

${ }^{\dagger}$ Björn Eliasson and Lars Fändriks contributed equally to this work.

${ }^{1}$ Institute of Medicine, University of Gothenburg, Gothenburg, Sweden

${ }^{2}$ Department of Medicine, Sahlgrenska University Hospital, 41345

Gothenburg, Sweden

Full list of author information is available at the end of the article
}

(c) The Author(s). 2020 Open Access This article is distributed under the terms of the Creative Commons Attribution 4.0 International License (http://creativecommons.org/licenses/by/4.0/), which permits unrestricted use, distribution, and reproduction in any medium, provided you give appropriate credit to the original author(s) and the source, provide a link to the Creative Commons license, and indicate if changes were made. The Creative Commons Public Domain Dedication waiver (http://creativecommons.org/publicdomain/zero/1.0/) applies to the data made available in this article, unless otherwise stated. 


\section{Background}

Bariatric surgery is an effective treatment of obesity as demonstrated by prospective cohort control studies, randomized control trials, and observational register-based studies [1-4]. In addition to sustained weight loss and improved well-being, comorbidities like type 2 diabetes improve after bariatric surgery, and risk of cardiovascular disease and premature death have been shown to be reduced when compared to conventional interventions, although there is also a panorama of potential side effects [5].

Despite the amount of literature focusing on effects of obesity treatments, the gap of knowledge on long-term complications remains. For example nutritional deficiencies, substance abuse, psychiatric as well as patientreported outcomes, might lead to unexpected and increased costs for society, along with suffering for the affected individual. In addition, it is unclear which surgical method has better long-term effects on weight and comorbidities. Furthermore, how do these surgical techniques compare to medical treatment in obese persons, who frequently exhibit co-morbidities and psychosocial conditions [6].

BASUN is a prospective study with 971 participants and 10 years of follow-up, that was initiated to observe the consequences of bariatric surgery and to compare these to effects of medical (non-surgical) treatment of obesity. The setting is the Regional Obesity Centre of Region Västra Götaland, through which obesity treatment in an eighth of the Swedish population is coordinated. Patients with obesity are a heterogenic group and choosing the most suitable treatment option can be challenging. The main aim of the study is to further assist in choosing the most beneficial treatment option for each patient without causing harm. The study covers a range of areas where significant data on long-term outcomes are lacking. The primary focus will be on comparing nutritional status after surgical and medical treatment. Secondary outcomes include changes in body composition, progression of psychiatric disorders, gastrointestinal symptoms, eating disorders, quality of life, levels of physical activity, effects of socioeconomic status and health economics. Some subjects will also participate in sub-studies addressing effects on bone metabolism or oral health.

The BASUN study will evaluate outcomes usually not reported in minor short-term studies, and describe groups of individuals at risk of long-term complications after treatment of obesity. The overall goal is to contribute to an improvement of the care and to reduce longterm adverse outcomes of surgical and medical treatment of obesity, and to define groups of individuals who demand further health care efforts before and after the interventions. This may result in a more equal health care for patients and the best possible use of public health care resources. In this paper we describe the design of the study as well as the baseline characteristics of the study population.

\section{Methods}

The BASUN study is a prospective non-randomized cohort study conducted in clinical practice, expanded with sampling of stool specimens and blood, questionnaires and data available in official registries and databases. We recruited study subjects by referral from the primary health care centres. All referrals for obesity treatment in Region Västra Götaland, Sweden, are centrally coordinated through a regional referral body, the Regional Obesity Centre (ROC), located at Sahlgrenska University Hospital in Gothenburg. The recruitment started in May 2015 and closed in November 2017. All persons willing and able to receive verbal and written information in Swedish about the study were invited after attending information meetings. The study subjects are planned for follow-up examinations at 2, 5, and 10 years.

\section{Obesity treatment}

Criteria for bariatric surgery in public healthcare in Sweden are in essence similar to those advocated in international guidelines, including $\mathrm{BMI}>35 \mathrm{~kg} / \mathrm{m}^{2}$ with obesity-related comorbidities such as diabetes and sleep apnoea, or BMI $>40 \mathrm{~kg} / \mathrm{m}^{2}$ without comorbidities [7]. Contraindications include drug or alcohol abuse, unstable psychiatric disorders, age under 18 years, cancer during the last 5 years, or poor general health condition [8]. A multidisciplinary board assesses the eligibility of all persons to undergo surgical treatment. Only Rouxen-Y gastric bypass (RYGB) or sleeve gastrectomy (SG) are used as the primary surgical procedure in the public health care in Sweden. Laparoscopic antecolic antegastric RYGB is carried out as previously described [9, 10]. Laparoscopic SG is carried out in line with state-of-the art principles described at the Fifth International Consensus Conference on SG [11]. The final choice of surgical method to be used in each individual case was made in consensus between the operating surgeon and the patient, taking into consideration the patients' preference as well medical conditions. Postoperative follow-up is conducted in accordance with Nordic guidelines for follow-up and dietary supplementation after bariatric surgery [12]. The operating unit conducts follow-up at 6 weeks, 6 and 12 months after surgery, then the patients are referred to their primary health care units that continue to do yearly follow-ups. All patients are prescribed dietary supplementation with iron $100 \mathrm{mg} /$ day, vitamin B12 $1 \mathrm{mg} /$ day, calcium $500 \mathrm{mg}$ and vitamin D $800 \mathrm{U}$ combinations twice daily, and multivitamin and mineral preparations containing at least $1,4 \mathrm{mg}$ thiamine, $400 \mu \mathrm{g}$ folate and $14 \mathrm{mg}$ zinc, twice daily. During the first 2 
months after surgery all operated patients were prescribed proton pump inhibitors, e. g. omeprazole $20 \mathrm{mg}$ once daily.

Medical treatment is offered to all persons 18 years of age or older with BMI $>35 \mathrm{~kg} / \mathrm{m}^{2}$, who do not qualify, or are not willing to undergo surgical treatment. If there are no contraindications, such as binge eating, severe psychological disturbance or medical condition, the intervention starts with a very low energy diet (VLED) period for 12, 16 or 20 weeks depending on the starting weight (BMI 35-39.9, 40-49.9 or $\geq 50 \mathrm{~kg} / \mathrm{m}^{2}$, respectively). During this period the daily intake is $450-800 \mathrm{kcal}$ as well as a recommended $1.5-2 \mathrm{~L}$ of fluids per day. The patients have appointments with a nurse at the start and then after 2, 5, 8 and 12 weeks.

The VLED period is followed by a period of food reintroduction lasting 12 weeks guided and monitored by a dietitian or clinical nutritionist. Each meal has an energy content of $300-475 \mathrm{kcal}$ and for every meal that was introduced monthly (breakfast, lunch, dinner) a VLED meal was removed. To estimate the energy need for each individual for weight reduction, the Harris Benedict sexspecific equations are used multiplied with a physical activity level of 1.3 to 1.4 and minus $30 \%$ representing the estimated energy deficit to achieve weight reduction [13]. After the food reintroduction period the patients continues with such energy-restricted diet. The dietary advice is based on the Nordic Nutrition Recommendation and each patient receives written instructions for a diet of $1400-1600 \mathrm{kcal}$ per day (15-20\% energy percent (E\%) protein, $30 \mathrm{E} \%$ fat and $50-55 \mathrm{E} \%$ carbohydrates) that was divided into three to five meals [13]. During the food reintroduction period, the patients had monthly appointments with a dietician for the remainder of the 12-month treatment period. The patients have appointments with a physician after 6 months and 12 months for addition of GLP-1 receptor agonists, SGLT-2 inhibitors, orlistat, or a combination of bupropion and naltrexone when appropriate as well as assessment of blood tests. Advice on physical activity was given by all professions at all visits.

\section{Demographic data and blood samples}

Demographic data at baseline was collected. This includes age, gender, civil status, working condition, education, community, country of birth, medication, comorbidities, smoking habits, and a 4-days dietary recall. Physical measurements were conducted regarding height and weight. Certain blood samples were analysed immediately, while additional blood samples were collected and stored in a biobank until future analysis. Results from blood work that was collected before the start of treatment was gathered from electronic medical records. Information on blood tests and measurements are given in Table 1.

\section{Self-evaluated validated questionnaires}

Specific questionnaires are completed by the study participants at baseline and will be completed at 2, 5 and 10 years of follow-up as shown in Table 2. The questionnaires cover three areas: gastrointestinal symptoms and eating problems, physical activity and quality of life, and psychological health.

\section{Assessment of gastrointestinal health and eating disorders}

We use four different questionnaires to investigate gastrointestinal symptoms and eating problems. The Bristol stool form scale (BSFS) evaluates bowel habits of all participants [14]. This is considered a useful marker for colonic transit. The Rome III criteria will be used to detect functional gastrointestinal disorders in our study. The 21-item Three Factor Eating Questionnaire (TFEQR21) is a scale with which three domains of eating behaviour are measured: cognitive restraint, uncontrolled eating and emotional eating [15]. It is used both in obese and non-obese individuals. The Questionnaire on Eating and Weight Patterns-Revised (QEWP-R) is a 27-item self-administered questionnaire for the diagnosis of binge eating disorder [16, 17].

\section{Assessment of levels of physical activity and quality of life}

Three different questionnaires are used to investigate physical activity and quality of life. The "Saltin Grimby" physical activity level scale is a four-level questionnaire used to assess physical activity in leisure time [18]. The RAND-36 is a widely used survey which assesses healthrelated quality of life [19]. EuroQol five-dimensional questionnaire (EQ-5D) is a standardized instrument designed to measure health related quality of life in various health conditions and treatments [20]. EQ-5D comprises five dimensions: mobility, self-care, everyday activities, pain/discomfort and anxiety/depression.

\section{Assessment of psychological health and substance abuse}

We also use four different questionnaires to investigate the psychological health among the study persons. Becks Anxiety Inventory (BAI) will measure the severity of anxiety in the study participants [21]. The Patient Health Questionnaire-9 (PHQ-9) is a self-reported measure of depression consisting of nine items matching the DSM-IV criteria of major depression, which will be used to detect depressive symptoms among the study participants [22]. To screen for ADHD, the ADHD Self Reporting Scale (ASRS) is used. ASRS was developed in collaboration with the World Health Organization (WHO) [23]. In addition, the Wender Utah Rating Scale (WURS) is used, that retrospectively assess childhood ADHD symptoms, to distinguish ADHD from disorders that present symptoms that overlap with ADHD symptoms such as bipolar disorder and borderline personality disorder [24]. Alcohol Use Disorders 
Table 1 Blood tests and measurements

\begin{tabular}{|c|c|c|}
\hline Blood samples for direct analysis & Collected from medical records & $\begin{array}{l}\text { Blood samples frozen } \\
\text { for later analysis }\end{array}$ \\
\hline $\begin{array}{l}\text { Complete blood cell counts (White blood cell count, red blood cell indices, } \\
\text { hemoglobin, erythrocyte and reticulocyte counts, hematocrit) }\end{array}$ & Liver function (ALAT, ASAT, bilirubin) $^{a}$ & \multirow{5}{*}{$\begin{array}{l}1 \text { EDTA } 4 \mathrm{ml}^{\mathrm{a}} \\
1 \text { EDTA, } 8,5 \mathrm{ml}^{\mathrm{a}} \\
2 \text { serum, } 8,5 \mathrm{ml}^{\mathrm{a}} \\
1 \text { Lithium heparin, 8,0 } \\
\mathrm{ml}^{\mathrm{a}}\end{array}$} \\
\hline Erythrocyte Sedimentation Rate ${ }^{a}$ & $\begin{array}{l}\text { Kidney function (serum creatinin, estimated } \\
\text { glomerular filtration rate, GFR) }\end{array}$ & \\
\hline Plasma glucose and $\mathrm{HbA} 1 \mathrm{c}^{\mathrm{a}}$ & $\begin{array}{l}\text { Blood lipids (HDL and LDL cholesterol, } \\
\text { triglycerides) }\end{array}$ & \\
\hline lonized calcium ${ }^{\mathrm{a}}$ & Thyroid function (fT4, TSH) ${ }^{a}$ & \\
\hline Stool samples ${ }^{\mathrm{b}}$ & & \\
\hline
\end{tabular}

${ }^{a}$ At baseline, 2 years, 5 years and 10 years

${ }^{\mathrm{b}}$ At baseline and 6 months

Identification Test (AUDIT), is used to identify individuals with harmful patterns of alcohol consumption. This was developed by WHO in 1992 [25]. Drug Use Disorders Identification Test (DUDIT) is used to screen individuals for drug related-problems. This was developed in Sweden in parallel to AUDIT and has been further evaluated [26, 27].

Within the study, there is a possibility to collect patient data from Swedish databases to be linked to data in the BASUN study. These databases are shown in Table 3 $[1,28-32]$.

\section{Statistical analysis}

In this report descriptive statistics were calculated using IBM SPSS 25.0. Continuous variables are reported as median with ranges as the variables were not normally distributed according to Shapiro Wilk test and visual inspection of boxplots. Categorical variables are reported as numbers (n) and proportions (\%). Kruskal-Wallis test was used for comparison of age, BMI, HbA1c, HDL and LDL cholesterol between the four treatment groups and Fisher's exact test for comparison of gender, marital status, education, smoking and pharmaceutical treatment. Further analysis of age and BMI were done using Mann Whitney $\mathrm{U}$ testing. The level of significance was set at $p<0.05$.

In future analyses of the data, Cox regressions and machine learning techniques will we used to evaluate importance of baseline conditions and characteristics for the long-term results in the three study groups.

\section{Results}

One thousand one hundred twenty-seven patients were invited to participate in the study, 832 females $(73,8 \%)$. Three hundred eighty-two patients were accepted for medical treatment, 589 for surgical treatment (388

Table 2 Questionnaires

\begin{tabular}{lll}
\hline Self-evaluated questionnaire & Outcome & Reference \\
\hline Bristol stool form scale (BSFS) & Bowel habits & Patel et al. 2015 [14] \\
Rome III criteria & Functional gastrointestinal disorders & \\
21-item Three Factor Eating Questionnaire (TFEQ-R21) & Eating behavior & Cappelleri et al. 2009 [15] \\
Questionnaire on Eating and Weight Patterns-Revised & Binge eating disorder & Borges et al. 2005 [16], Dorflinger et al. \\
(QEWP-R) & & Grimby et al. 2015 [18] \\
"Saltin Grimby" physical activity level scale & Physical activity & Krops et al. 2018 [19] \\
RAND-36 item healty survey & Health-related quality of life & Sullivan et al. 2016 [20] \\
EuroQol five-dimensional questionnaire (EQ-5D) & Health-related quality of life & Steer et al. 1997 [21] \\
Becks Anxiety Inventory (BAl) & Symptoms of anxiety & Kroenke et al. 2001 [22] \\
Patient Health Questionnaire-9 (PHQ-9) & Symptoms of depression & Kessler et al. 2005 [23] \\
ADHD Self Reporting Scale (ASRS) & ADHD screening & Ward et al. 1993 [24] \\
Wender Utah Rating Scale (WURS) & Distinguish ADHD from other psychological & \\
Alcohol Use Disorders Identification Test (AUDIT) & Aisorders & Babor et al. 2001 [25] \\
Drug Use Disorders Identification Test (DUDIT) & Drug related-problems & Berman et al. 2003 [26], Hildebrand et al. \\
\end{tabular}


Table 3 Swedish databases linked to study

\begin{tabular}{|c|c|c|}
\hline Databases & Specific area & Reference \\
\hline $\begin{array}{l}\text { Scandinavian Obesity Surgery } \\
\text { Register }\end{array}$ & $\begin{array}{l}\text { Obesity post bariatric } \\
\text { surgery }\end{array}$ & Hedenbro JL et al. 2015 [28] \\
\hline The National Diabetes Register & Diabetes Mellitus & Eliasson B et al. 2015 [1] \\
\hline $\begin{array}{l}\text { Swedish National Inpatient } \\
\text { Register }\end{array}$ & Diagnosis of diseases & Ludvigsson JG et al. 2011 [29] \\
\hline $\begin{array}{l}\text { Swedish Child Health Care } \\
\text { Register }\end{array}$ & Child healthcare & Emilsson et al. 2015 [30] \\
\hline Swedish Prescribed Drug Register & Medication & Wettermark et al. 2007 [31] \\
\hline Swedish Fracture Register & Nonspinal skeleton injury & Wennergren et al. 2015 [32] \\
\hline Swedish Social Insurance Agency & Sick leave & $\begin{array}{l}\text { www.government.se/government-agencies/social-insurance-agency\%2D\%2 } \\
\text { Dforsakringskassan }\end{array}$ \\
\hline $\begin{array}{l}\text { Swedish Public Employment } \\
\text { Service }\end{array}$ & Employment & www.government.se/government-agencies/swedish-public-employment-service/ \\
\hline Statistics Sweden (SCB) & Public statistics & www.scb.se/en \\
\hline
\end{tabular}

RYGB and 201 SG) and 156 patients left the study without treatment. That left a study population of 971 patients, as described in Fig. 1. Clinical characteristics and treatments of the individuals in the three groups at baseline are given in Table 4. There were possible differences between the groups with regards to age and BMI. The differences were apparent between medical treatment group and gastric bypass group as well as between the medical group and the gastric sleeve group according to Mann Whitney U analysis. There were no significant differences between the groups regarding distribution of sex, education, pharmaceutical treatment for diabetes,

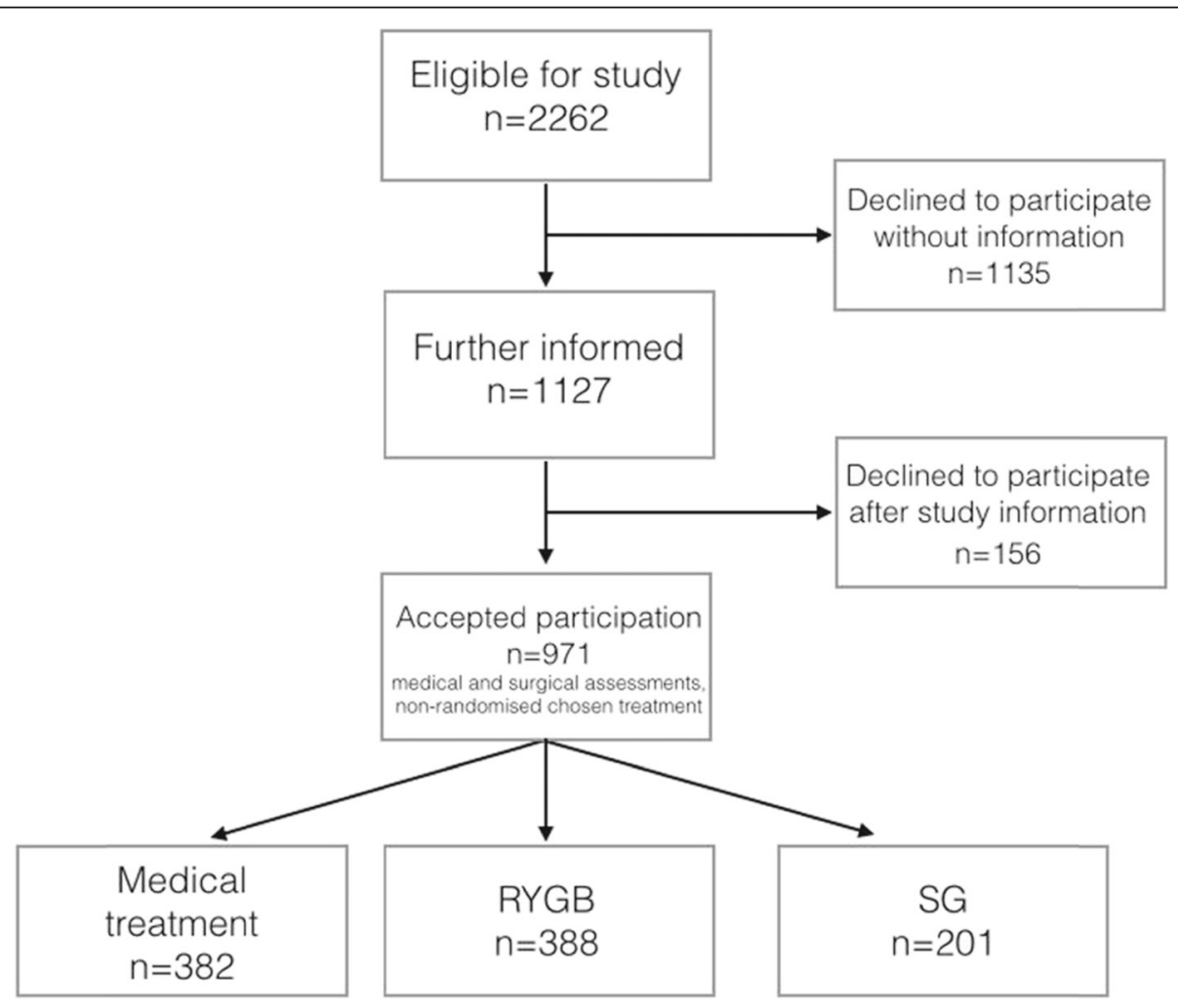

Legend: GBP: Roux-en-Y gastric bypass, SG: Sleeve gastrectomy.

Fig. 1 Participants. GBP: Roux-en-Y gastric bypass, SG: Sleeve gastrectomy 
Table 4 Baseline characteristics

\begin{tabular}{|c|c|c|c|c|}
\hline & MT $(n=382)$ & RYGB $(n=388)$ & SG $(n=201)$ & $P$ \\
\hline Female & $276(72,3)$ & $301(77,6)$ & $152(75,6)$ & 0.206 \\
\hline Age (years) & $49.0(18-78)$ & $43.5(18-62)$ & $41(18-63)$ & $<0.0001$ \\
\hline BMI $\left(\mathrm{kg} / \mathrm{m}^{2}\right)$ & $40.1(31.6-90.4)$ & $41.8(34.8-65.3)$ & $41.6(35-63.7)$ & $<0.0001$ \\
\hline $\mathrm{HbA1c}(\mathrm{mmol} / \mathrm{mol})$ & $36(25.0-95.0)$ & $37(26-118)$ & $36(27-73)$ & 0.173 \\
\hline $\mathrm{HDL}(\mathrm{mmol} / \mathrm{l})$ & $1.3(0.6-2.6)$ & $1.2(0.4-2.3)$ & $1.2(0.7-2.0)$ & 0,003 \\
\hline LDL (mmol/l) & $3.1(1.2-6.7)$ & $3.2(0.8-6.2)$ & $3.3(0.9-5.7)$ & 0.627 \\
\hline Glucose lowering treatment & $55(14,4)$ & $55(14,2)$ & $28(13,9)$ & 0.990 \\
\hline Blood pressure lowering treatment & $135(35,3)$ & $112(28,9)$ & $58(28,9)$ & 0.109 \\
\hline Lipid lowering treatment & $52(13,6)$ & $51(13,1)$ & $23(11,4)$ & 0.768 \\
\hline Treatment for anxiety/depression & $85(22,3)$ & $68(17,5)$ & $52(25,9)$ & 0.101 \\
\hline Treatment with antipsychotics & $13(3,4)$ & $4(1,0)$ & $6(3,0)$ & 0.078 \\
\hline Pain medication & $80(20,9)$ & $63(16,2)$ & $38(18,9)$ & 0.238 \\
\hline Hypothyroidism treatment & $49(12,8)$ & $42(10,8)$ & $26(12,9)$ & 0.613 \\
\hline ADHD treatment & $8(2,1)$ & $2(0,5)$ & $2(1)$ & 0.124 \\
\hline Iron supplements & $5(1,3)$ & $3(0,8)$ & $3(1,5)$ & 0.685 \\
\hline B-vitamin supplements & $14(3,7)$ & $9(2,3)$ & $9(4,5)$ & 0.313 \\
\hline D-vitamin supplements & $3(0,8)$ & $7(1,8)$ & $4(2,0)$ & 0.347 \\
\hline Folic acid supplements & $6(1,6)$ & $4(1,0)$ & $6(3,0)$ & 0.221 \\
\hline Calcium supplements & $6(1,6)$ & $1(0,3)$ & $0(0)$ & 0.055 \\
\hline Protonpump inhibitor treatment & $50(13,1)$ & $39(10,1)$ & $30(14,9)$ & 0.180 \\
\hline Education & & & & 0.082 \\
\hline Elementary & $51(13,4)$ & $42(10,8)$ & $15(7,5)$ & \\
\hline Secondary & $141(36,9)$ & $199(51,3)$ & $98(48,8)$ & \\
\hline Tertiary & $127(33,2)$ & $101(26,0)$ & $69(34,3)$ & \\
\hline Smoking & $23(6,0)$ & $24(6,2)$ & $13(6,5)$ & 0.884 \\
\hline Married/cohabitation & $206(53,9)$ & $242(62,4)$ & $121(60,2)$ & 0.955 \\
\hline
\end{tabular}

Data are $\mathrm{n}(\%)$ or median (range)

MT Medical treatment, GBP Roux-en-Y gastric bypass, SG Sleeve gastrectomy, BMI Body mass index, HDL High-density lipoprotein, LDL Low-density lipoprotein

hypertension, hyperlipidemia, pain, anxiety and depression, gastric reflux, hypothyroidism, attention deficit hyperactivity disorder or treatment for deficiency of iron, vitamin B12, vitamin D, folic acid and calcium. The differences between the groups with regards to treatment with antipsychotics, smoking, and marital status were not significant either. When examined, there were differences in levels of high-density lipoproteins but the groups were similar with regards to levels of low-density lipoproteins. Further analysis of the group that left the study without starting treatment can be seen in Fig. 2a and b.

\section{Discussion}

The BASUN study will follow 971 obese subjects treated with the best surgical and medical methods currently available for up to 10 years in clinical practice. We here present a description of the study methodology as well as baseline characteristics of the study population.
The size of the study population and the length of follow-up are clear strengths of the study. This large cohort is representative for this group of patients in the Western region of Sweden with a population of approximately 2 million individuals since the treatment of severe obesity is centralized in this part of the country. Another major advantage of the study is the access to national databases to collect patient information which simplifies follow-up and reduces risk for unexplained drop outs. BASUN includes all patients that meet criteria for the treatment of severe obesity, not only focusing on patients with established comorbidities as diabetes, as in many other studies, e.g., the STAMPEDE study [33]. BASUN also does not only compare the effects of medical treatment and surgery, but also the two most commonly used surgical methods used today, Roux-en-Y gastric bypass and sleeve gastrectomy.

The fact that the patients were not randomized to different treatment options can be seen as a limitation of 
a. Medical treatment

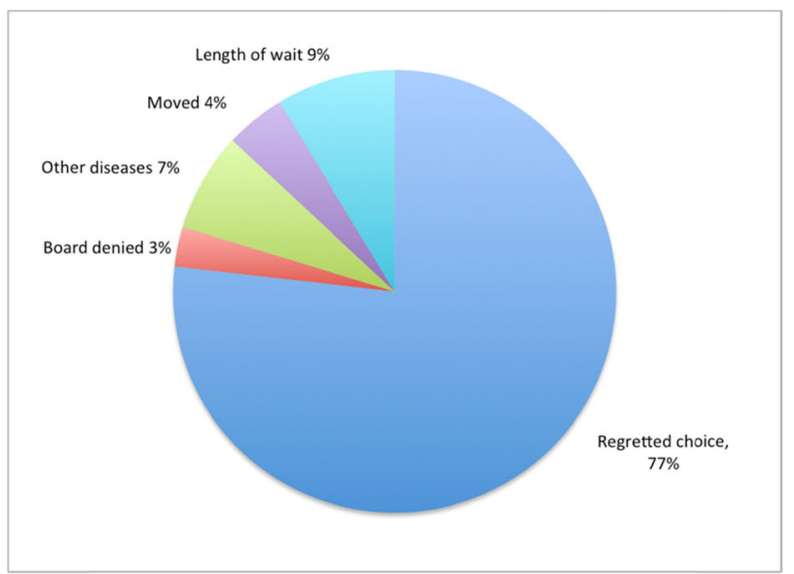

Legend figure 2a: $\mathrm{n}=69$. Reasons for declined treatment in medical treatment group after information on study was given.

b. Surgical treatment

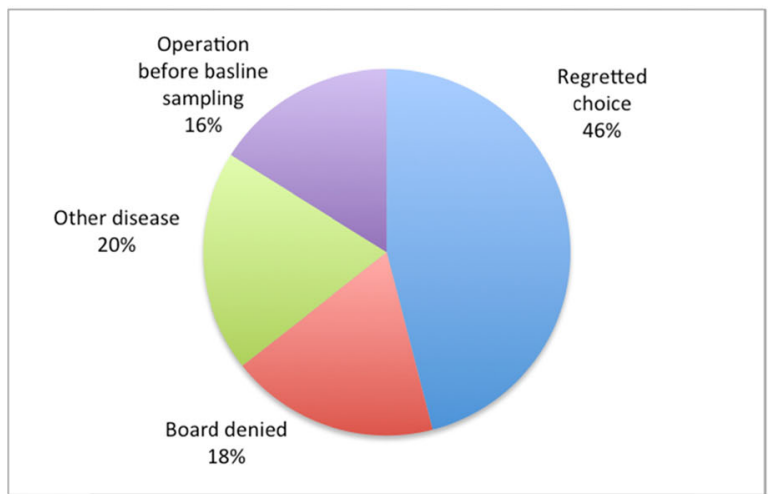

Legend 2b: $\mathrm{n}=87$. Reasons for declined treatment in surgical treatment group after information on study was given.

Fig. 2 Patients that declined to participate in study. 2a. Medical treatment. a $n=69$. Reasons for declined treatment in medical treatment group after information on study was given. $\mathbf{b}$ Surgical treatment. $n=87$. Reasons for declined treatment in surgical treatment group after information on study was given

the study. Randomizing the patients was not possible as we wanted to compare outcomes of the treatments for all obese subjects at our centre in clinical practice, also for those that were not primarily interested in or hade contraindications for surgical treatment. Patient involvement in the choice of treatment is representative for real life and can also be seen as a strength of the study. This also explains why the groups differ slightly at baseline. In our practice, we are more restrictive with offering surgery to patients above 60 years of age due to the suggested higher risk of complications and presumably lower benefit. Older patients can be accepted for medical treatment and this explains the slight difference in age between the medical group and the two surgical groups. The groups were similar with regards to pharmaceutical treatment, including treatment with vitamins and minerals, which indicates a comparable status of patient health before the start of treatment. Levels of education, marital status and smoking were similar between the groups and should therefore not be confounding factors. Within the scope of BASUN, we do not follow persons with language barriers, or unwillingness to participate, which could affect the interpretation of future results.

The clinical characteristics of the BASUN cohort resembles the participants of the Swedish Obese Subjects (SOS), which is a study that has been crucial to the widespread use of obesity surgery [34]. Many comparative studies have focused on intensive lifestyle and dietary changes with or without the addition of pharmaceuticals. It has already been shown that these medical treatments are not comparable in effectiveness to bariatric surgery. In type 2 diabetes, the Look Ahead study showed that 
cardiovascular risk is only reduced with a weight loss of at least $10 \%$ of body weight and most medical treatment programs do not lead to mean weight loss of that magnitude [35]. Programs that involve very low-calorie diets, however, can result in large weight loss as well as diabetes remission, as recently shown by the DiRECT study [36]. Such treatment might therefore be more comparable to bariatric surgery in the short-term. The main criticism of LED or VLED has been that the weight loss after longer follow-up than 12 months is not well documented. The medical treatment arm in BASUN is, however, a combination of LED, dietary advice under the food reintroduction period, as well as the possible addition or adjustment of pharmaceutical treatment. In Sweden, the same supplement treatment is recommended for RYGB and SG patients postoperatively. A study recently published by Aarts and colleagues confirmed the need for postoperative nutritional management after SG [37] and suggested that larger doses may be required. Earlier studies have focused on nutritional management after malabsorptive surgery [38, 39].

The BASUN study will assist in identifying which factors are important when it comes to the choice of treatment for obesity, and further aim to define responders and non-responders of surgery and medical treatment. Sub-studies will also be initiated, addressing potential long-term adverse effects of bariatric surgery such as osteoporosis, pre- and postoperative nutritional deficiencies, gastrointestinal function, psychiatric disorders and dental health. These have not all been sufficiently studied previously.

\section{Conclusion}

In summary, BASUN seeks to describe in detail short and long-term effects of bariatric surgery and compare the outcomes of currently available surgical and medical treatments for obesity in clinical practice. The ultimate goal is to reduce complications of treatment and focus public health resources where they benefit the patient the most by defining risk patients before the start of treatment.

\section{Abbreviations}

BMI: Body mass index; MT: Medical treatment; RYGB: Roux-en-Y gastric bypass; SG: Sleeve gastrectomy; T2D: Type 2 diabetes

\section{Acknowledgements}

Dr. Malin Werling initiated the BASUN study. Professor Lars Fändriks is the principal investigator and professor Björn Eliasson is co-investigator.

\section{Authors' contributions}

$\mathrm{GH}, \mathrm{KM}, \mathrm{WW}, \mathrm{AN}, \mathrm{WB}, \mathrm{SL}, \mathrm{CB}, \mathrm{MW}, \mathrm{BE}$ and LF contributed to the conception and design of this manuscript. WB and SL contributed to the acquisition of data and GH and SL performed the statistical analyses. GH, KM, WW, AN, WB, $S L, C B, M W, B E$ and LF contributed to the interpretation of data. GH, KM, AN and $B E$ drafted the article, and $G H, K M, W W, A N, W B, S L, C B, M W, B E$ and $L F$ contributed to the critical revision of the article. LF and BE are the guarantors of this work and, as such, had full access to all the data in the study and takes responsibility for the integrity of the data and the accuracy of the data analysis. GH, KM, WW, AN, WB, SL, CB, MW, BE and LF have agreed to be personally accountable for their contributions and ensure that all questions raised in regards to the accuracy of the work will be appropriately investigated, resolved and resolution documented. GH, KM, VW, AN, WB, SL, $\mathrm{CB}, \mathrm{MW}, \mathrm{BE}$ and $\mathrm{LF}$ read and approved with final manuscript.

\section{Funding}

The study was financed Region Västra Götaland and by grants from the Swedish state under the agreement between the Swedish government and the country councils, the ALF-agreement (ALFGBG-725291), as well as the Novo Nordisk Foundation. The funders have no roll in the design of the study, collection, analysis, or interpretation of data or in writing the manuscript.

\section{Availability of data and materials}

Data and material are not available due to the nature of this prospective study. The datasets used and/or analysed during the current study available from the corresponding author on reasonable request.

\section{Ethics approval and consent to participate}

Dr. no 673-14 (2014-09-24), Ethical Regional Board of Gothenburg, Gothenburg, Sweden. The ethics committee belongs to the Swedish Ethical Review Authority at the Government Offices of Sweden.

Study nurse obtained written and verbal informed consent from study participants.

\section{Consent for publication}

Does not apply.

\section{Competing interests}

Professor Eliasson reports personal fees (expert panels, lectures) from Amgen, AstraZeneca, Boehringer Ingelheim, Eli Lilly, Merck Sharp \& Dohme, Mundipharma, Navamedic, NovoNordisk, RLS Global, and grants and personal fees from Sanofi, all outside the submitted work.

\section{Author details}

${ }^{1}$ Institute of Medicine, University of Gothenburg, Gothenburg, Sweden. ${ }^{2}$ Department of Medicine, Sahlgrenska University Hospital, 41345 Gothenburg, Sweden. ${ }^{3}$ Institute of Clinical Sciences, University of Gothenburg, Gothenburg, Sweden. ${ }^{4}$ Department of Surgery, Sahlgrenska University Hospital, Gothenburg, Sweden. ${ }^{5}$ Department of Cardiology, Sahlgrenska University Hospital, Gothenburg, Sweden. ${ }^{6}$ Department of Public Health and Community Medicine, Sahlgrenska University Hospital, Gothenburg, Sweden.

Received: 11 November 2019 Accepted: 11 February 2020

Published online: 14 February 2020

\section{References}

1. Eliasson B, Liakopoulos V, Franzen S, Naslund I, Svensson AM, Ottosson J, et al. Cardiovascular disease and mortality in patients with type 2 diabetes after bariatric surgery in Sweden: a nationwide, matched, observational cohort study. Lancet Diabetes Endocrinol. 2015;3(11):847-54.

2. O'Brien PE, Hindle A, Brennan L, Skinner S, Burton P, Smith A, et al. Longterm outcomes after bariatric surgery: a systematic review and meta-analysis of weight loss at 10 or more years for all bariatric procedures and a singlecentre review of 20-year outcomes after adjustable gastric banding. Obes Surg. 2019;29(1):3-14.

3. Sjostrom L, Narbro K, Sjostrom CD, Karason K, Larsson B, Wedel H, et al. Effects of bariatric surgery on mortality in Swedish obese subjects. N Engl J Med. 2007;357(8):741-52.

4. Schauer PR, Bhatt DL, Kashyap SR. Bariatric surgery or intensive medical therapy for diabetes after 5 years. N Engl J Med. 2017;376(20):1997.

5. Khorgami Z, Shoar S, Saber AA, Howard CA, Danaei G, Sclabas GM. Outcomes of bariatric surgery versus medical management for type 2 diabetes mellitus: a meta-analysis of randomized controlled trials. Obes Surg. 2019;29(3):964-74.

6. Rajan TM, Menon V. Psychiatric disorders and obesity: a review of association studies. J Postgrad Med. 2017;63(3):182-90.

7. NIH conference. Gastrointestinal surgery for severe obesity. Consensus development conference panel. Ann Intern Med. 1991;115(12):956-61. 
8. Fried M, Yumuk V, Oppert JM, Scopinaro N, Torres A, Weiner R, et al. Interdisciplinary European guidelines on metabolic and bariatric surgery. Obes Surg. 2014;24(1):42-55.

9. $\quad$ Lonroth H. Laparoscopic gastric bypass. Obes Surg. 1998;8(6):563-5.

10. Olbers T, Lonroth H, Fagevik-Olsen M, Lundell L. Laparoscopic gastric bypass: development of technique, respiratory function, and long-term outcome. Obes Surg. 2003;13(3):364-70

11. Gagner M, Hutchinson C, Rosenthal R. Fifth international consensus conference: current status of sleeve gastrectomy. Surg Obes Relat Dis. 2016; 12(4):750-6.

12. Laurenius A, Naslund I, Sandvik J, Videhult P, Wiren M. Lakartidningen; 2018. p. 115.

13. Frankenfield DC, Muth ER, Rowe WA. The Harris-Benedict studies of human basal metabolism: history and limitations. J Am Diet Assoc. 1998;98(4):439-45.

14. Patel P, Bercik P, Morgan DG, Bolino C, Pintos-Sanchez MI, Moayyedi P, et al. Prevalence of organic disease at colonoscopy in patients with symptoms compatible with irritable bowel syndrome: cross-sectional survey. Scand J Gastroenterol. 2015;50(7):816-23.

15. Cappelleri JC, Bushmakin AG, Gerber RA, Leidy NK, Sexton CC, Lowe MR, et al. Psychometric analysis of the three-factor eating questionnaire-R21: results from a large diverse sample of obese and non-obese participants. Int J Obes. 2009;33(6):611-20.

16. Borges MB, Morgan CM, Claudino AM, da Silveira DX. Validation of the Portuguese version of the Questionnaire on Eating and Weight PatternsRevised (QEWP-R) for the screening of binge eating disorder. Braz J Psychiatry. 2005;27(4):319-22.

17. Dorflinger $L M$, Ruser $C B$, Masheb RM. A brief screening measure for binge eating in primary care. Eat Behav. 2017;26:163-6.

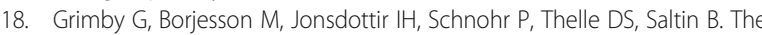
"Saltin-Grimby physical activity level scale" and its application to health research. Scand J Med Sci Sports. 2015;25(Suppl 4):119-25.

19. Krops LA, Wolthuizen L, Dijkstra PU, Jaarsma EA, Geertzen JHB, Dekker R. Reliability of translation of the RAND 36-item health survey in a postrehabilitation population. Int J Rehabil Res. 2018;41(2):128-37.

20. Sullivan PW, Ghushchyan VH. EQ-5D scores for diabetes-related comorbidities. Value Health. 2016;19(8):1002-8.

21. Steer RA, Beck AT. Beck anxiety inventory. In: Wood CPZRJ, editor. Evaluating stress: a book of resources. Lanham: Scarecrow Education; 1997. p. $23-40$.

22. Kroenke K, Spitzer RL, Williams JB. The PHQ-9: validity of a brief depression severity measure. J Gen Intern Med. 2001;16(9):606-13.

23. Kessler RC, Adler L, Ames M, Demler O, Faraone S, Hiripi E, et al. The World Health Organization Adult ADHD Self-Report Scale (ASRS): a short screening scale for use in the general population. Psychol Med. 2005:35(2):245-56.

24. Ward MF, Wender PH, Reimherr FW. The Wender Utah rating scale: an aid in the retrospective diagnosis of childhood attention deficit hyperactivity disorder. Am J Psychiatry. 1993;150(6):885-90.

25. Babor TFH-BJ, Saunders JB, Monteiro MG. AUDIT: the alcohol use disorders identification test guidelines for use in primary care (second edition). Geneva: World Health Organization; 2001.

26. Berman AHBH, Palmstierna T, Schlyter F. DUDIT, drug use disorders identification test. Stockholm: Karolinska Instututet; 2003.

27. Hildebrand M. The psychometric properties of the Drug Use Disorders Identification Test (DUDIT): a review of recent research. J Subst Abus Treat. 2015;53:52-9.

28. Hedenbro JL, Naslund E, Boman L, Lundegardh G, Bylund A, Ekelund M, et al. Formation of the Scandinavian obesity surgery registry, SOReg. Obes Surg. 2015;25(10):1893-900

29. Ludvigsson JF, Andersson E, Ekbom A, Feychting M, Kim JL, Reuterwall C, et al. External review and validation of the Swedish national inpatient register. BMC Public Health. 2011:11:450.

30. Emilsson L, Lindahl B, Koster M, Lambe M, Ludvigsson JF. Review of 103 Swedish healthcare quality registries. J Intern Med. 2015;277(1):94-136.

31. Wettermark B, Hammar N, Fored CM, Leimanis A, Otterblad Olausson P, Bergman $U$, et al. The new Swedish prescribed drug register--opportunities for pharmacoepidemiological research and experience from the first six months. Pharmacoepidemiol Drug Saf. 2007;16(7):726-35.

32. Wennergren D, Ekholm C, Sandelin A, Moller M. The Swedish fracture register: 103,000 fractures registered. BMC Musculoskelet Disord. 2015;16:338
33. Schauer PR, Bhatt DL, Kirwan JP, Wolski K, Aminian A, Brethauer SA, et al. Bariatric surgery versus intensive medical therapy for diabetes - 5-year outcomes. N Engl J Med. 2017;376(7):641-51.

34. Sjostrom L. Review of the key results from the Swedish Obese Subjects (SOS) trial - a prospective controlled intervention study of bariatric surgery. Intern Med. 2013;273(3):219-34.

35. Look ARG, Gregg EW, Jakicic JM, Blackburn G, Bloomquist P, Bray GA, et al. Association of the magnitude of weight loss and changes in physical fitness with long-term cardiovascular disease outcomes in overweight or obese people with type 2 diabetes: a post-hoc analysis of the Look AHEAD randomised clinical trial. Lancet Diabetes Endocrinol. 2016:4(11):913-21.

36. Lean ME, Leslie WS, Barnes AC, Brosnahan N, Thom G, McCombie L, et al. Primary care-led weight management for remission of type 2 diabetes (DiRECT): an open-label, cluster-randomised trial. Lancet. 2018;391(10120): 541-51.

37. Heusschen L, Schijns W, Ploeger N. et al. OBES SURG. 2019. https://doi.org/ 10.1007/s11695-019-04252-1.

38. Heber D, Greenway FL, Kaplan LM, Livingston E, Salvador J, Still C. Endocrine and nutritional management of the post-bariatric surgery patient: an endocrine society clinical practice guideline. J Clin Endocrinol Metab. 2010; 95(11):4823-43.

39. Dogan K, Homan J, Aarts EO, de Boer H, van Laarhoven C, Berends FJ. Longterm nutritional status in patients following Roux-en-Y gastric bypass surgery. Clin Nutr. 2018;37(2):612-7.

\section{Publisher's Note}

Springer Nature remains neutral with regard to jurisdictional claims in published maps and institutional affiliations.
Ready to submit your research? Choose BMC and benefit from:

- fast, convenient online submission

- thorough peer review by experienced researchers in your field

- rapid publication on acceptance

- support for research data, including large and complex data types

- gold Open Access which fosters wider collaboration and increased citations

- maximum visibility for your research: over $100 \mathrm{M}$ website views per year

At $\mathrm{BMC}$, research is always in progress.

Learn more biomedcentral.com/submissions 